\title{
Allostatic load amplifies the effect of blood lead levels on elevated blood pressure among middle-aged U.S. adults: a cross-sectional study
}

\author{
Ami R Zota ${ }^{1,2}$, Edmond D Shenassa ${ }^{3}$ and Rachel Morello-Frosch ${ }^{4 *}$
}

\begin{abstract}
Background: Scientists and regulators have sought to understand whether and how physiologic dysregulation due to chronic stress exposure may enhance vulnerability to the adverse health effects of toxicant exposures. We conducted a cross-sectional study to determine whether allostatic load (AL), a composite measure of physiologic response to chronic exposure to stress, amplifies the effect of lead exposure on blood pressure among middle-aged adults.

Methods: We analyzed associations between blood lead levels and blood pressure in a nationally representative sample of 8,194 U.S. adults (aged 40-65 years) participating in the National Health and Nutritional Examination Survey, 1999--2008. Outcomes were elevated systolic ( $\geq 140 \mathrm{~mm} \mathrm{Hg}$ ) and diastolic ( $\geq 90 \mathrm{~mm} \mathrm{Hg}$ ) blood pressure. AL was defined as the aggregate score of seven components, reflecting dysregulation of the cardiovascular, inflammatory, and endocrine systems.
\end{abstract}

Results: Logistic regression models showed a linear dose-response relationship for quintiles of blood lead and elevated systolic blood pressure in the high AL group $(p=0.03)$ but not the low AL group $(p=0.24)$. Similarly, the relationship between lead exposure and elevated diastolic blood pressure was stronger among the high AL group than the low AL group. Within the high AL group, the fourth and fifth quintiles had significantly elevated odds of elevated blood pressure compared to lowest quintile $[\mathrm{OR}=1.92,(95 \% \mathrm{Cl}, 1.07,3.47)$ and $\mathrm{OR}=2.28(95 \% \mathrm{Cl}, 1.33,3.91)$, respectively]. In the low AL group, none of the quintile effects were significantly different than the referent group although there was evidence of a linear trend ( $p=0.03$ ). The lead by AL interaction term was not statistically significant for either systolic or diastolic blood pressure models.

Conclusions: Results suggest that higher AL may amplify the adverse effects of lead on blood pressure. Future research should assess the implications of cumulative exposures to environmental and social stressors for regulatory decision-making.

Keywords: Blood pressure, Cumulative impacts, Environmental health, Lead, Stress

\section{Background}

Regulatory agencies and environmental health scientists are beginning to examine whether and how chronic stress exposure potentially amplifies human vulnerability to the adverse health effects of toxicant exposures [1]. Emerging evidence suggests that cumulative physiological "wear and tear" resulting from chronic over-activity of the body's stress-response system may impair immune functioning

\footnotetext{
* Correspondence: rmf@berkeley.edu

${ }^{4}$ Department of Environmental Science, Policy and Management and School of Public Health, University of California, Berkeley, California, USA

Full list of author information is available at the end of the article
}

and increase vulnerability to environmental stressors [2] by increasing the absorption of toxicants into the body through increased respiration, perspiration, and consumption [3]; compromising the body's defense systems against toxicants; affecting the same physiological processes as environmental agents; and directly causing illness $[4,5]$.

High blood pressure is a common condition among U.S. adults and a major risk factor for strokes, heart attacks, congestive heart failure, and kidney disease [6,7]. Minority and lower socio-economic status (SES) populations are at elevated risk of hypertension [6]. These populations also encounter the double jeopardy of elevated

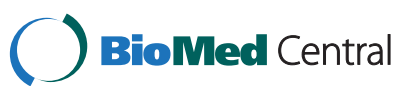


exposures to environmental hazards combined with chronic social stressors $[8,9]$. While the root causes of hypertension remain poorly understood, growing evidence indicates that the interaction of environmental, social, and genetic factors may partially explain the persistent racial and socioeconomic disparities in cardiovascular outcomes, such as hypertension [10-12].

Lead is a ubiquitous environmental contaminant that can impair the cardiovascular system. Although lead was removed from gasoline and household paint in the 1970s, the general population, and low SES populations in particular, continue to be exposed to lead through occupational exposures, lead-based paint in older housing stock, and the gradual release of lead from bone, which serves as the body's principal, long term repository for this pollutant [13]. Cross-sectional and longitudinal epidemiologic studies demonstrate associations between lead exposure and elevated blood pressure including development of hypertension [14-17]. Animal studies have confirmed this relationship and elucidated mechanisms by which lead may influence blood pressure regulation [18]. A systematic review by Navas-Acien et al. [19] concluded that the evidence was sufficient to infer a causal relationship between lead exposure and hypertension.

Chronic stress has also been associated with hypertension [20] and may interact with lead to stimulate the hypothalamic-pituitary-adrenal (HPA) axis, promote oxidative stress and inflammation, augment adrenergic activity, and alter the renin-angiotensin system [18,21,22], which are critical to blood pressure regulation. Chronic stress may result from myriad experiences such as job stress, racial discrimination, and place-based stressors such as lack of basic services, and exposure to violence [23-26]. Allostasis refers to how the body's stress-response systems regulate internal physiology in response to chronic exposure to physical, social, and environmental stressors [27]. Allostatic load (AL) refers to the cumulative biological burden exacted by ongoing dysregulation of the stress-response due to chronic stress exposure $[2,27,28]$. AL encompasses physiologic dysregulation of multiple systems affected by overactivation of the HPA axis including, but not limited to, the central nervous system, cardiovascular, immune, inflammatory, and endocrine systems [29]. Previous studies have linked higher AL scores with increased risk of agingrelated health outcomes such as incident cardiovascular disease, decline in physical functioning, decline in cognitive function, and mortality [30-32]. Therefore, allostatic load is a composite biomarker of the cumulative biological burden exacted by ongoing disruption of the body's stressresponse system [33] that may increase vulnerability to the adverse health effects of toxicants, such as lead [8].

While potential synergistic effects between chronic stress and lead exposures on blood pressure are biologically plausible, only one epidemiologic study has examined these interactions. Peters et al. [34] reported a significant interaction between bone lead exposures and self-reported measures of stress on the development of hypertension among a cohort of older, white men in the Boston area. However, no previous study has examined whether AL amplifies vulnerability to the adverse health effects of exposures to environmental toxicants, in particular, lead. We hypothesized that middle-aged adults with higher AL would be more vulnerable to the lead-induced effects on blood pressure than adults with lower AL. To test this hypothesis, we evaluated the association between blood lead level and elevated systolic and diastolic blood pressure in a cross-sectional study of middle-aged men and women from the United States (U.S.). We then stratified our sample between high versus low AL to examine differences in effect estimates between these two groups.

\section{Methods}

\section{Study population}

The National Health and Nutritional Examination Survey (NHANES), conducted by the Centers for Disease Control and Prevention $(\mathrm{CDC})$, are a nationally representative survey and physical examination of the health and nutritional status of the civilian, non-institutionalized U.S. population. The survey also includes measurement of environmental chemicals in blood and urine (Further information at http://www.cdc.gov/nchs/nhanes.htm). NHANES obtained informed consent from all study participants. Due to the complex survey design, separate sample weights are assigned to each survey participant; each participant represents approximately 50000 other U.S. residents.

The present study combines participants from five cycles of NHANES, spanning the years 1999 to 2008. African Americans, Mexican Americans, and low-income persons were oversampled in these survey cycles [35]. In this study, we restricted the study population to the 9918 participants who were 40-65 years of age to minimize the effect of confounding by age, which is strongly associated with lead exposure, blood pressure, and AL $[7,14,36]$. Of these, we excluded participants who were missing measurements of blood lead, blood pressure, components of AL, any model covariates or who were currently pregnant $(\mathrm{N}=1724)$, leaving a total of 8194 eligible participants for our analyses.

\section{Blood pressure outcomes}

Three consecutive measurements of systolic and diastolic blood pressures were taken during the NHANES physical examination by certified examiners. We used the mean of systolic and diastolic blood pressure measurements in our analyses unless only one measurement was available. Elevated systolic blood pressure was defined as systolic blood pressure $\geq 140 \mathrm{~mm} \mathrm{Hg}$. Elevated diastolic blood pressure was defined as diastolic blood pressure $\geq 90 \mathrm{~mm} \mathrm{Hg}$. We did not evaluate clinical 
hypertension as an outcome, but instead included selfreported antihypertensive medication use as a separate covariate in regression models. We chose this analytical approach because people diagnosed with hypertension who are taking medication may exhibit different health behaviors from those who have undiagnosed and/or untreated elevated blood pressure which in turn, may affect lead, allostatic load, and hypertension relationships. In our study population, antihypertensive medication users had significantly lower serum cotinine and alcohol consumption levels than people with elevated blood pressure who were not on medication (data not shown).

\section{Blood lead measurements}

Blood samples were obtained by venipuncture during the physical examination, and lead concentrations were quantified using inductively coupled plasma mass spectrometry (CDC National Center for Environmental Health, Atlanta, Georgia). Twelve participants $(<1 \%)$ had blood lead concentrations below the limit of detection (LOD) $(0.30 \mu \mathrm{g} /$ $\mathrm{dL}$ ) which were substituted by the CDC with LOD $\sqrt{2}$.

\section{Allostatic load}

Informed by prior studies $[37,38]$ as well as data availability within NHANES, we operationalized AL by creating a cumulative index of physiologic dysregulation of the cardiovascular, inflammatory, and endocrine systems using the following seven biological markers: urinary creatinine, serum albumin, urinary C-reactive proteins (biomarkers of inflammation and immune response), plasma levels of glycosolated hemoglobin, serum triglycerides, HDL serum cholesterol (metabolic and cardiovascular biomarkers), and waist circumference (anthropometric biomarker). Cutpoints were empirically defined using sex-specific quintiles for each of the seven components. A value of one was assigned to the lowest quintile and a value of five was assigned to the highest quintile. The highest quintile always corresponded to the highest risk category (e.g. large waist circumference, low creatinine clearance). We calculated the AL score by summing each participant's rankings for the seven components; the AL score ranged from seven to 35 .

\section{Statistical analyses}

We calculated the mean and standard error (SE) for normally distributed variables such as systolic and diastolic blood pressures, and geometric mean (GM) and geometric standard error (GSE) for lognormally distributed variables such as lead and cotinine. In bivariate analyses, differences across groups were evaluated using the chi square test for categorical data and analysis of variance for continuous data.

We examined the association between lead exposure and blood pressure in several ways. In our primary analysis, we modeled systolic and diastolic blood pressure as dichotomous variables using logistic regression. To allow for potential non-linear relationships, we categorized lead exposure into quintiles and compared quintiles two, three, four, and five to the lowest quintile. Quintile cutoffs were based on the weighted distribution of lead. We also modeled both the blood pressure and lead exposure as continuous variables. In these models, blood lead concentrations were natural $\log$ transformed prior to construction of multivariate models.

In addition to blood lead, the model included the following biologic and social determinants of hypertension: age (continuous), race/ethnicity (non-Hispanic white, nonHispanic black, Mexican American, other Hispanic, or other race), educational attainment [less than 12th grade (no diploma), high school graduate, some college/associates (AA) degree, or college graduate and above], and sex. We adjusted all models for self-reported use of antihypertensive medication (yes/no). The following potential confounders were also considered: marital status (married/ living with partner, divorced/separated/widowed, or never married), smoking status (never, former, current), and alcohol consumption (never, $<1$ drink per week, 1-3 drinks per week, or $>3$ drinks per week). These covariates were retained in the final model if they were statistically significant or if they changed the beta coefficient for lead exposure by $10 \%$ or more.

To assess for potential effect modification by AL, we stratified the final multivariate model of blood lead and elevated blood pressure by AL status divided at the median AL score. To formally test the interactions observed in our stratified models, we included a lead by allostatic load interaction term in our full model along with crossproduct terms of AL with all covariates in the final model (e.g. AL*sex, AL*age, etc.). To assess the impact of our definition of "high AL", we conducted a sensitivity analysis where high AL was defined as an AL score above the 80th percentile. Lastly, to evaluate the impact of antihypertensive medication users on our results, we conducted a sensitivity analysis by removing antihypertensive medication users $(n=1640)$ from the final multivariate models.

All analyses were conducted in SUDAAN 10.0 (Research Triangle Institute, Cary, NC) and SAS 9.2 (SAS Institute Inc., Cary, NC). SUDAAN calculates variance estimates after incorporating the non-random sampling design and the sample population weights, which account for the unequal probability of selection into the survey and the oversampling of certain subgroups. Since we combined five cycles of data, we calculated new sample weights for each study participant according to the NHANES analytical guidelines [39]. For participants surveyed from 1999-2002, sample weights were equal to two-fifths of the four year sample weights. For participants surveyed from 2003-2008, sample weights were 
Table 1 Descriptive characteristics for adults aged 40 to 65 years $(N=8194)$ in the national health and nutritional examination survey, United States, 1999-2008 ${ }^{\mathrm{a}}$

\begin{tabular}{|c|c|c|c|c|c|c|c|}
\hline \multirow[b]{2}{*}{ Characteristic } & \multirow[b]{2}{*}{$\begin{array}{c}\text { Total } \\
(\mathrm{N}=\mathbf{8 1 9 4}) \\
\end{array}$} & \multicolumn{5}{|c|}{ Blood lead quintile } & \\
\hline & & $\begin{array}{l}\text { Quintile } 1 \\
(\mathrm{~N}=1411)\end{array}$ & $\begin{array}{l}\text { Quintile } 2 \\
(\mathrm{~N}=1510)\end{array}$ & $\begin{array}{l}\text { Quintile } 3 \\
(\mathrm{~N}=1608)\end{array}$ & $\begin{array}{l}\text { Quintile } 4 \\
(\mathrm{~N}=1638)\end{array}$ & $\begin{array}{l}\text { Quintile } 5 \\
(\mathrm{~N}=2027)\end{array}$ & \\
\hline Blood lead ( $\mu \mathrm{g} / \mathrm{dL}) ;$ geometric mean (GSE) & $1.69(0.02)$ & $0.76(0.01)$ & $1.25(0.00)$ & $1.67(0.00)$ & $2.25(0.01)$ & $3.88(0.03)$ & $* *$ \\
\hline Systolic blood pressure (mm Hg); mean (SE) & $124.33(0.30)$ & $122.23(0.55)$ & $122.43(0.53)$ & $124.59(0.49)$ & $125.48(0.57)$ & $126.92(0.62)$ & $* *$ \\
\hline Diastolic blood pressure (mm Hg); mean (SE) & $74.81(0.20)$ & $74.30(0.37)$ & $74.16(0.38)$ & $74.99(0.32)$ & $74.96(0.32)$ & $75.65(0.34)$ & ** \\
\hline \multicolumn{7}{|l|}{ Elevated blood pressure, \% (SE) } & \\
\hline Systolic > 140 mm Hg & $16.4(0.6)$ & $13.9(1.2)$ & $13.3(1.1)$ & $15.9(1.2)$ & $17.5(1.0)$ & $21.4(1.4)$ & ** \\
\hline Diastolic $>90$ mm Hg & $7.8(0.5)$ & $5.5(0.7)$ & $6.5(0.8)$ & $8.1(0.9)$ & $9.2(0.9)$ & $9.6(0.8)$ & ** \\
\hline Age (years), mean (SE) & $50.9(0.15)$ & $48.4(0.22)$ & $50.0(0.25)$ & $51.3(0.27)$ & $52.2(0.26)$ & $52.6(0.21)$ & $* *$ \\
\hline Male sex, \% (SE) & $49.1(0.6)$ & $25.1(1.7)$ & $39.3(1.5)$ & $51.8(1.4)$ & $59.0(1.5)$ & $70.5(1.5)$ & ** \\
\hline \multicolumn{7}{|l|}{ Race/Ethnicity, \% (SE) } & $* *$ \\
\hline Non-Hispanic White & $75.7(1.3)$ & $80.1(1.6)$ & $77.9(1.7)$ & $77.6(1.4)$ & $74.5(1.6)$ & $68.3(2.1)$ & \\
\hline Non-Hispanic Black & $9.7(0.8)$ & $6.7(0.7)$ & $8.3(0.8)$ & $8.8(0.9)$ & $9.9(0.9)$ & $14.8(1.4)$ & \\
\hline Mexican American & $5.7(0.6)$ & $5.3(0.7)$ & $5.2(0.6)$ & $5.5(0.7)$ & $5.4(0.6)$ & $7.2(0.9)$ & \\
\hline Other Hispanic & $4.2(0.6)$ & $4.0(0.7)$ & $4.6(1.1)$ & $4.4(0.9)$ & $4.1(0.7)$ & $4.1(0.9)$ & \\
\hline Other & $4.7(0.4)$ & $3.9(0.7)$ & $4.0(0.7)$ & $3.7(0.6)$ & $6.1(0.9)$ & $5.6(0.8)$ & \\
\hline \multicolumn{7}{|l|}{ Educational attainment, \% (SE) } & ** \\
\hline Less than 9th grade & $5.4(0.4)$ & $3.2(0.4)$ & $4.2(0.5)$ & $5.7(0.7)$ & $5.6(0.6)$ & $8.3(0.7)$ & \\
\hline 9th - 12th grade (no diploma) & $10.9(0.5)$ & $7.4(0.9)$ & $9.1(0.8)$ & $8.7(0.9)$ & $12.1(0.9)$ & $17.3(1.2)$ & \\
\hline High school graduate or equivalent & $24.6(0.8)$ & $22.7(1.5)$ & $22.9(1.5)$ & $24.6(1.4)$ & $26.0(1.5)$ & $26.7(1.4)$ & \\
\hline Some college or associates (AA) degree & $30.6(0.8)$ & $32.0(1.5)$ & $30.3(1.7)$ & $32.1(1.3)$ & $29.5(1.6)$ & $29.3(1.1)$ & \\
\hline College graduate or above & $28.5(1.2)$ & $34.7(2.0)$ & $33.5(2.0)$ & $28.9(1.9)$ & $26.9(1.7)$ & $18.3(1.4)$ & \\
\hline \multicolumn{7}{|l|}{ Marital status, \% (SE) } & ** \\
\hline Married or living with partner & $73.2(0.8)$ & $75.6(1.6)$ & $75.6(1.2)$ & $72.6(1.4)$ & $71.4(1.5)$ & $70.8(1.4)$ & \\
\hline Divorced, separated, or widowed & $19.9(0.7)$ & $17.5(1.4)$ & $18.3(1.2)$ & $20.0(1.2)$ & $22.2(1.4)$ & $21.6(1.3)$ & \\
\hline Never married & $6.9(0.4)$ & $6.9(0.8)$ & $6.1(0.8)$ & $7.4(0.9)$ & $6.4(0.7)$ & $7.7(0.8)$ & \\
\hline \multicolumn{7}{|l|}{ Smoking status, \% (SE) } & $* *$ \\
\hline Never & $47.2(0.8)$ & $69.1(1.5)$ & $56.4(1.6)$ & $45.4(1.7)$ & $36.3(1.6)$ & $28.9(1.3)$ & \\
\hline Former & $28.9(0.7)$ & $23.4(1.3)$ & $27.4(1.5)$ & $31.6(1.4)$ & $31.0(1.3)$ & $31.1(1.4)$ & \\
\hline Current & $23.9(0.8)$ & $7.4(0.8)$ & $16.2(1.1)$ & $23.0(1.5)$ & $32.7(1.8)$ & $40.0(1.4)$ & \\
\hline \multicolumn{7}{|l|}{ Alcohol consumption, \% (SE) } & $* *$ \\
\hline None & $25.5(1.0)$ & $36.9(2.0)$ & $30.0(1.6)$ & $22.1(1.3)$ & $21.8(1.3)$ & $16.6(1.2)$ & \\
\hline Less than 1 drink per week & $34.8(0.9)$ & $39.9(1.7)$ & $36.6(1.5)$ & $34.8(1.6)$ & $31.3(1.4)$ & $31.5(1.6)$ & \\
\hline 1 to 3 drinks per week & $11.4(0.5)$ & $12.6(1.1)$ & $13.0(1.1)$ & $13.0(1.0)$ & $10.4(0.9)$ & $8.1(0.7)$ & \\
\hline 3 or more drinks per week & $28.3(0.9)$ & $10.6(1.2)$ & $20.4(1.3)$ & $30.2(1.7)$ & $36.6(1.5)$ & $43.8(1.7)$ & \\
\hline Use of antihypertensive medication, \% (SE) & $23.5(0.7)$ & $26.3(1.5)$ & $22.4(1.5)$ & $21.9(1.3)$ & $23.1(1.3)$ & $23.7(1.4)$ & \\
\hline
\end{tabular}

Abbreviations: GSE geometric standard error, SE standard error.

a All estimates are adjusted for survey design and sample weights. Differences across groups were evaluated using the chi square test for categorical data and analysis of variance for continuous data. ${ }^{* *} P<0.05$.

equal to one fifth of the two year sample weights. Statistical tests for trends of categorical variables were conducted by coding quintile categories as integers and evaluating tests for significance on the slope of the regression line. A (two-sided) $P$-value $<0.05$ was considered significant and $<0.10$ marginally significant.

\section{Results}

Participant characteristics

We excluded participants who were missing data or were pregnant $(\mathrm{N}=1724)$, leaving a total of 8194 participants for our analyses. There were no significant differences in mean levels of blood lead concentration, blood pressure, 
or in the frequency of blood pressure medication use between the eligible and excluded groups. However, the excluded group had a higher prevalence of systolic and diastolic hypertension and a lower mean allostatic load score. Those not included were also more likely to be younger, female, non-Hispanic black or other/mixed race, less educated, never married, current or former smokers, and less likely to regularly drink alcohol (data not shown).

In our final study sample, blood lead levels in the highest lead quintile were approximately five times higher than those in the lowest lead quintile (GM $($ GSE) $=3.88(0.03)$ $\mu \mathrm{g} / \mathrm{dL}$ versus $0.76(0.01) \mu \mathrm{g} / \mathrm{dL})$. Participants in the higher lead quintiles were more likely to be older, male, nonHispanic black, less educated, current smokers, and regular drinkers (Table 1). Systolic and diastolic blood pressures increased positively by blood lead quintile $(P<0.01)$ while use of antihypertensive medication was similar across lead quintiles (Table 1 ).

Distribution of blood lead quintiles varied by AL status, and elevated blood pressures were more prevalent in the high AL group (Table 2). Antihypertensive medication use was approximately twice as common in the high AL group compared to the low AL group. We observed a significant inverse relationship between educational attainment and
$\mathrm{AL}$, and $\mathrm{AL}$ varied by race/ethnicity with non-Hispanic Whites having the lowest AL score and Hispanics having the highest AL score. Differences between Hispanics (both Mexican American and other Hispanics) and nonHispanic Whites were statistically significant $(P<0.001)$ while differences between non-Hispanic Whites and nonHispanic Blacks were not (data not shown).

\section{Lead, allostatic load, and elevated blood pressure}

In linear regression models for blood pressure modeled continuously, lead exposure was a significant predictor of elevated diastolic but not systolic blood pressure after adjustment for covariates (Table 3). Diastolic blood pressure was significantly higher in the fourth and fifth lead exposure quintiles relative to the reference quintile, and there was evidence of a linear, dose-response relationship ( $P=0.0001$ for trend). When models were stratified by high versus low $\mathrm{AL}$, the association between lead and systolic blood pressure was not significant in either of the AL groups. For diastolic blood pressure, we observed positive associations between lead exposure and diastolic blood pressure in both AL groups. The highest lead quintile had a larger effect on diastolic blood pressure among the high AL group ( $\beta=2.01 ; 95 \% \mathrm{CI}, 0.24,3.79$ ) than in the low AL group ( $\beta=1.79 ; 95 \% \mathrm{CI}, 0.62,2.95)$,

\section{Table 2 Distribution of blood pressure measures, lead exposure, and allostatic load components by allostatic load score among adults aged 40 to 65 years in the national health and nutritional examination survey, United States, 1999-2008 ( $\mathrm{N}=8194)$}

\begin{tabular}{|c|c|c|}
\hline Variable & Low allostatic load ${ }^{\mathrm{a}}(\mathrm{N}=4069)$ & High allostatic load ${ }^{\mathrm{a}}(\mathrm{N}=4125)$ \\
\hline \multicolumn{3}{|l|}{ Blood pressure, \% (SE) } \\
\hline Elevated systolic blood pressure & $12.8(0.8)$ & $20.7(0.8)$ \\
\hline Elevated diastolic blood pressure & $6.9(0.5)$ & $8.8(0.6)$ \\
\hline \multicolumn{3}{|l|}{$\mathrm{Pb}$ Exposure, \% (SE) } \\
\hline Quintile $1(\leq 1.05 \mu \mathrm{g} / \mathrm{dL})$ & $17.5(1.0)$ & $22.9(1.0)$ \\
\hline Quintile $2(1.06-1.44 \mu \mathrm{g} / \mathrm{dL})$ & $20.1(0.9)$ & $19.9(0.8)$ \\
\hline Quintile $3(1.45-1.90 \mu \mathrm{g} / \mathrm{dL})$ & $20.7(0.9)$ & $19.3(0.8)$ \\
\hline Quintile 4 (1.91 - $2.69 \mu \mathrm{g} / \mathrm{dL})$ & $19.9(0.7)$ & $19.5(0.9)$ \\
\hline Quintile 5 (> $2.70 \mu \mathrm{g} / \mathrm{dL})$ & $21.8(0.8)$ & $18.5(0.8)$ \\
\hline Antihypertensive medication use, \% (SE) & $15.7(0.7)$ & $32.8(0.9)$ \\
\hline Components of Allostatic Load & \multicolumn{2}{|c|}{ mean \pm SE (range) } \\
\hline Triglycerides (mg/dL), & $115.3 \pm 1.56(26-1000)$ & $222.3 \pm 4.02(31-3854)$ \\
\hline HDL cholesterol (mg/dL) & $59.8 \pm 0.35(8-164)$ & $44.9 \pm 0.27(12-108)$ \\
\hline Waist circumference (cm) & $91.8 \pm 0.23(59.4-157.1)$ & $108.35 \pm 0.32(70.7-168.4)$ \\
\hline C-reactive protein (mg/dL) & $0.23 \pm 0.01(0.01-17.5)$ & $0.66 \pm 0.02(0.01-18.5)$ \\
\hline Creatinine (mg/dL) & $123.66 \pm 1.49(7-609)$ & $112.86 \pm 1.61(7-774)$ \\
\hline Albumin (g/dL) & $4.38 \pm 0.01(2.5-5.3)$ & $4.16 \pm 0.01(2.3-5.3)$ \\
\hline Glycosolated hemoglobin (\%) & $5.31 \pm 0.01(3.3-14.0)$ & $5.95 \pm 0.02(4.1-18.8)$ \\
\hline Composite allostatic load score & $16.9 \pm 0.02(7-21)$ & $25.7 \pm 0.06(22-35)$ \\
\hline
\end{tabular}

${ }^{\mathrm{a}}$ Low allostatic load is equal to a score between 7 and 20. High allostatic load is equal to a score between 21 and 35 . Elevated systolic BP defined as average BP $\geq$ $140 \mathrm{~mm} \mathrm{Hg}$ and elevated diastolic BP defined as average BP $\geq 90 \mathrm{~mm} \mathrm{Hg}$. 
Table 3 Adjusted difference in systolic and diastolic blood pressure by quintiles of blood lead exposure among adults aged 40 to 65 years in the national health and nutritional examination survey, United States, 1999-2008 ${ }^{\mathrm{a}}$

\begin{tabular}{|c|c|c|c|c|c|c|}
\hline & \multicolumn{2}{|c|}{ All participants $(\mathrm{N}=8,194)$} & \multicolumn{2}{|c|}{ Low allostatic load $(\mathrm{N}=4,069)$} & \multicolumn{2}{|c|}{ High allostatic load $(\mathrm{N}=4,125)$} \\
\hline & Difference & $95 \% \mathrm{Cl}$ & Difference & $95 \% \mathrm{Cl}$ & Difference & $95 \% \mathrm{Cl}$ \\
\hline \multicolumn{7}{|c|}{ Systolic blood pressure $(\mathrm{mm} \mathrm{Hg})^{c}$} \\
\hline \multicolumn{7}{|c|}{$\mathrm{Pb}$ Exposure } \\
\hline Quintile 1 & 0 & Reference & 0 & Reference & 0 & Reference \\
\hline Quintile 2 & -0.79 & $-2.07,0.49$ & -1.08 & $-2.40,0.25$ & 0.13 & $-2.17,2.44$ \\
\hline Quintile 3 & 0.24 & $-1.22,1.71$ & -0.27 & $-2.09,1.55$ & 1.68 & $-0.65,4.02$ \\
\hline Quintile 4 & 0.20 & $-1.26,1.67$ & 0.20 & $-1.59,1.98$ & 0.97 & $-1.50,3.44$ \\
\hline Quintile 5 & 0.63 & $-1.07,2.33$ & 0.67 & $-1.24,2.58$ & 1.60 & $-0.62,3.82$ \\
\hline Test for trend & \multicolumn{2}{|c|}{$P=0.24$} & \multicolumn{2}{|c|}{$P=0.21$} & \multicolumn{2}{|c|}{$P=0.14$} \\
\hline \multicolumn{7}{|c|}{ Diastolic blood pressure $(\mathrm{mm} \mathrm{Hg})^{d}$} \\
\hline \multicolumn{7}{|c|}{$\mathrm{Pb}$ Exposure } \\
\hline Quintile 1 & 0 & Reference & 0 & Reference & 0 & Reference \\
\hline Quintile 2 & 0.08 & $-0.80,0.97$ & -0.30 & $-1.60,1.01$ & 0.80 & $-0.51,2.11$ \\
\hline Quintile 3 & 0.99 & $0.16,1.82$ & 1.06 & $0.03,2.09$ & 1.23 & $-0.11,2.57$ \\
\hline Quintile 4 & 1.17 & $0.25,2.08$ & 1.36 & $0.11,2.60$ & 1.21 & $-0.21,2.63$ \\
\hline Quintile 5 & 1.76 & $0.75,2.78$ & 1.79 & $0.62,2.95$ & 2.01 & $0.24,3.79$ \\
\hline Test for trend & \multicolumn{2}{|c|}{$P=0.0001$} & \multicolumn{2}{|c|}{$P=0.0002$} & \multicolumn{2}{|c|}{$P=0.02$} \\
\hline
\end{tabular}

Abbreviations: $\mathrm{Cl}$ confidence interval.

${ }^{a}$ Adjusted for age, sex, race/ethnicity, education, marital status, smoking status, alcohol consumption, and antihypertensive medication use.

bLow allostatic load is equal to a score between 7 and 20. High allostatic load is equal to a score between 21 and 35 .

${ }^{\mathrm{C}} \mathrm{Pb}$ and $\mathrm{AL}$ test of interaction for systolic blood pressure: $P=0.75$.

${ }^{\mathrm{d}} \mathrm{Pb}$ and $\mathrm{AL}$ test of interaction for diastolic blood pressure: $P=0.77$.

although the lead by AL interaction term was not statistically significant (Table 3).

The effect of lead was more apparent when blood pressure outcomes were modeled dichotomously using clinical cutoffs for elevated blood pressure (Table 4). There was evidence of a linear dose-response for quintiles of blood lead and elevated systolic blood pressure in the high AL group $(\mathrm{p}=0.03)$ but not the low $\mathrm{AL}$ group $(p=0.24)$. Similarly, the relationship between lead exposure and elevated diastolic blood pressure was stronger among the high $\mathrm{AL}$ group than the low $\mathrm{AL}$ group. Within the high AL group, the fourth and fifth quintiles had significantly increased odds of elevated blood pressure compared to lowest quintile $[\mathrm{OR}=1.92$, (95\% CI, 1.07, 3.47) and OR $=2.28$ (95\% CI, 1.33, 3.91), respectively] and there was evidence of a linear, doseresponse relationships $(\mathrm{p}=0.002)$. In the low AL group, none of the quintile effects were significantly different than the referent group although there was evidence of a linear trend ( $\mathrm{p}=0.03)$. The lead by AL interaction term was not statistically significant for either systolic or diastolic blood pressure models.

We also conducted several sensitivity analyses to examine the impact of model selection and AL definitions on the results. A more extreme definition for high AL (i.e., the top $80 \%$ ), rendered larger differences in effect estimates for lead exposure between low and high AL groups (Figure 1). However, these estimates also had wider confidence intervals and the lead by AL interaction terms were not statistically significant. We also examined effects of lead exposure modeled continuously. These results, which are presented in Additional file 1: Tables S1 and Additional file 2: Table S2, were generally similar to models in which lead exposure was modeled in quintiles.

After removing antihypertensive medication users from the analysis (Additional file 3: Tables S3 and Additional file 4: Table S4), effect estimates for lead exposure on differences in systolic blood pressure remained null in both groups. However, in logistic regression models, lead effects on odds of elevated systolic blood pressure in the highest quintile were more pronounced in the high AL group (OR $=1.75,(95 \%$ CI: $1.09,2.83)$ compared to the low AL group $(\mathrm{OR}=1.08,(95 \% \mathrm{CI}: 0.63,1.84)$. Effect estimates for lead exposure on differences in diastolic blood pressure in this restricted model were similar to those obtained in the full model. However, lead effects on the odds of elevated diastolic blood pressure were attenuated in both groups, The odds ratio for the fifth quintile relative to the reference quintile was 1.33 (95\% CI: $0.65,2.73)$ and 1.82 (95\% CI: $0.91,3.64)$, in the low and high AL group, respectively, and the linear dose response trends in either group were no longer statistically significant. 
Table 4 Adjusted odds ratio for elevated systolic and diastolic blood pressure by quintiles of blood lead exposure among adults aged 40 to 65 years in the national health and nutritional examination survey, United States, 1999-2008 ${ }^{\mathrm{a}}$

\begin{tabular}{|c|c|c|c|c|c|c|}
\hline & \multicolumn{2}{|c|}{ All participants $(\mathrm{N}=8,194)$} & \multicolumn{2}{|c|}{ Low allostatic load $(\mathrm{N}=4,069)$} & \multicolumn{2}{|c|}{ High allostatic load ${ }^{\mathrm{b}}(\mathrm{N}=4,125)$} \\
\hline & OR & $95 \% \mathrm{Cl}$ & OR & $95 \% \mathrm{Cl}$ & OR & $95 \% \mathrm{Cl}$ \\
\hline \multicolumn{7}{|c|}{ Elevated systolic blood pressure $(\geq 140 \mathrm{~mm} \mathrm{Hg})^{c}$} \\
\hline \multicolumn{7}{|l|}{$\mathrm{Pb}$ Exposure } \\
\hline Quintile 1 & 1.00 & Reference & 1.00 & Reference & 1.00 & Reference \\
\hline Quintile 2 & 0.87 & $0.66,1.15$ & 0.81 & $0.55,1.19$ & 0.96 & $0.66,1.38$ \\
\hline Quintile 3 & 1.00 & $0.76,1.31$ & 0.86 & $0.61,1.21$ & 1.20 & $0.82,1.75$ \\
\hline Quintile 4 & 1.03 & $0.78,1.37$ & 0.88 & $0.56,1.39$ & 1.23 & $0.86,1.76$ \\
\hline Quintile 5 & 1.23 & $0.92,1.65$ & 1.14 & $0.79,1.66$ & 1.40 & $0.99,1.97$ \\
\hline Test for trend & \multicolumn{2}{|c|}{$P=0.06$} & \multicolumn{2}{|c|}{$P=0.24$} & \multicolumn{2}{|c|}{$P=0.03$} \\
\hline \multicolumn{7}{|c|}{ Elevated diastolic blood pressure $(\geq 90 \mathrm{~mm} \mathrm{Hg})^{d}$} \\
\hline \multicolumn{7}{|l|}{$\mathrm{Pb}$ Exposure } \\
\hline Quintile 1 & 1.00 & Reference & 1.00 & Reference & 1.00 & Reference \\
\hline Quintile 2 & 1.22 & $0.82,1.81$ & 0.85 & $0.45,1.60$ & 1.66 & $0.93,2.95$ \\
\hline Quintile 3 & 1.56 & $1.11,2.19$ & 1.51 & $0.83,2.75$ & 1.67 & $0.97,2.85$ \\
\hline Quintile 4 & 1.80 & $1.24,2.60$ & 1.73 & $0.96,3.12$ & 1.92 & $1.07,3.47$ \\
\hline Quintile 5 & 1.77 & $1.25,2.50$ & 1.46 & $0.80,2.68$ & 2.28 & $1.33,3.91$ \\
\hline Test for trend & \multicolumn{2}{|c|}{$P=0.0002$} & \multicolumn{2}{|c|}{$P=0.03$} & \multicolumn{2}{|c|}{$P=0.002$} \\
\hline
\end{tabular}

Abbreviations: $\mathrm{Cl}$ confidence interval, $\mathrm{OR}$ odds ratio.

${ }^{a}$ Adjusted for age, sex, race/ethnicity, education, marital status, smoking status, alcohol consumption, and antihypertensive medication use.

${ }^{b}$ Low allostatic load is equal to a score between 7 and 20. High allostatic load is equal to a score between 21 and 35 .

${ }^{\mathrm{C}} \mathrm{Pb}$ and $\mathrm{AL}$ test of interaction for elevated systolic blood pressure: $P=0.74$.

${ }^{\mathrm{d}} \mathrm{Pb}$ and $\mathrm{AL}$ test of interaction for elevated diastolic blood pressure: $P=0.40$.

\section{Discussion}

Interpretation of the results and underlying mechanisms

In this cross-sectional study of a nationally representative population of U.S. middle-aged adults, we found slightly higher effect estimates of low-level lead exposure on the risk of elevated blood pressure among participants with relatively higher AL. Higher blood lead levels were significantly associated with increased odds of elevated systolic and diastolic blood pressure among adults with high AL, a biologic indicator of chronic stress response, while lead effects on blood pressure were less pronounced and not significant for those in the low $\mathrm{AL}$ group. P-values for multiplicative interactions between lead and AL were not significant. Although this is the first examination of whether higher AL may amplify vulnerability to the adverse effects of lead exposure, our findings are consistent with interactions between lead and psychosocial stressors observed in animals [40], and in human studies [34,41,42]. Lead and chronic stress may impact several common biological pathways which could, in turn, affect blood pressure regulation. Most importantly, both chronic stress and lead can influence the HPA axis, which can promote inflammation, vasoconstriction, and adrenergic activity. Lead and chronic stress can also increase the level of reactive oxygen species leading to oxidative stress $[18,22,43]$. Stronger effects of lead exposure on blood pressure among participants with higher AL may be a consequence of the direct effect of lead on components of the physiological stress response system underlying the AL measure. For example, previous studies have found associations between blood lead and general distress [44] and bone lead and phobic anxiety [45]. However, in our study, the distribution of lead exposure was similar between participants with high versus low AL. Moreover, we observed significant dose-response relationships between lead and blood pressure among the high AL group, particularly for the diastolic blood pressure outcome. The consistency of this stronger effect across different lead levels and health outcomes suggests that AL may in fact amplify the blood lead and blood pressure relationship.

\section{Comparison with other studies}

Our study supports a growing body of epidemiological evidence indicating that physiologic dysregulation due to chronic stress may amplify observed associations between environmental pollutant exposures and adverse health outcomes $[4,5,8,23,46]$. Peters et al. [34] examined the modifying effects of self-reported stress on the relationship between bone lead and hypertension in a longitudinal cohort of older white men from the greater Boston area. They found that men with higher bone lead concentrations and higher levels of stress are at 


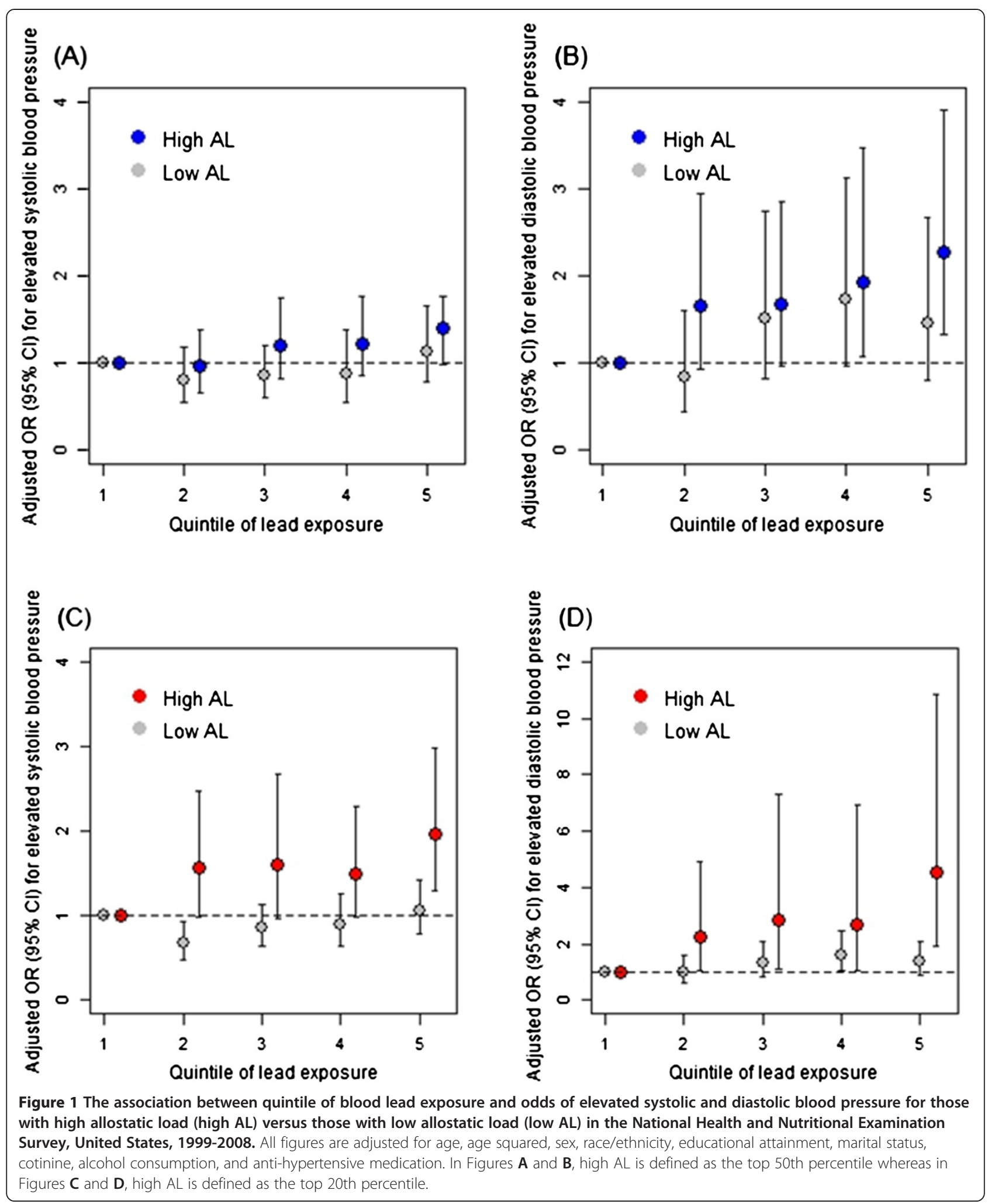

increased risk of developing hypertension than those with lower stress levels. In cross-sectional analyses of subjects without hypertension at baseline, they found an interactive effect between lead and stress for systolic blood pressure but not diastolic blood pressure. In this study, we observed stronger lead effects by AL on diastolic blood pressure for various model specifications. Among the high AL group in the main analyses (Table 4), effect estimates 
of lead were larger for risk of elevated diastolic blood pressure than systolic blood pressure. When participants taking hypertensive medications were removed in the sensitivity analysis (Additional file 3: Table S3 and Additional file 4: Table S4), stronger effects were still observed among the higher AL group for diastolic blood pressure in the linear regression models, but these effects were non-significant in the logistic models (Additional file 4: Table S4).

Results of most previous studies report small but significant effects of lead exposure on both systolic and diastolic blood pressure $[15,16]$. Some studies report stronger effects on diastolic blood pressure whereas in other studies the reverse is true [16]. These inconsistencies may result from differences in ranges of lead exposures, age of study participants, measurement error associated with blood pressure determination, and covariates included in the analysis. For example, systolic blood pressure increases linearly with age, whereas diastolic blood pressure increases with age up to 55 and then declines [7]. Therefore, elevated diastolic blood pressure may be more common among our study population of middle-aged adults than studies with older populations. Indeed, our results showing lead exposure effects on diastolic blood pressure across all participants (Tables 3 and 4) are consistent with those from another study that examined effects of blood lead levels on elevated blood pressure among women aged 40-59 years from the NHANES III survey [47].

\section{Strengths and limitations}

We had a large, heterogeneous study population which enhanced our ability to detect effects of lead exposure on blood pressure among participants with relatively higher AL. The racial and economic diversity provided by the NHANES sampling strategy is particularly useful for this analysis since lead exposures and AL scores were both socioeconomically patterned. Moreover, we were able to control for a number of potential confounders including: age, educational attainment, race/ethnicity, smoking, alcohol consumption, marital status, and antihypertensive medication use. However, residual confounding remains possible. In addition, the cross-sectional design of our study precludes a systemic assessment of the temporality of lead exposure and allostatic load, the potential for reverse causation between hypertension and $\mathrm{AL}$, or the potential effects of cumulative lead exposures throughout the life course, since blood lead (as opposed to bone lead) mostly reflects recent and ongoing exposures as well as lead that has been mobilized from tissue stores such as bone [48]. Nevertheless, although our study could not address these limitations, we did systematically evaluate the robustness of our findings with different model specifications, and our results generally persisted in sensitivity analyses.
Most human health studies analyzing whether chronic stress exposure amplifies associations between pollutant exposures and adverse health outcomes have relied on self-assessments of chronic stress exposure, or individual and area-level SES metrics as proxies for stress exposure $[23,34,41,49,50]$. This is the first study to assess whether physiologic dysregulation as measured by allostatic load, amplifies vulnerability to the adverse health effects of toxicant exposures. Importantly, we used the NHANES data set that did not include the primary mediators of HPA axis activity (e.g. cortisol, epinephrine, norepinephrine, dehydroepiandrosterone sulfate (DHEA-S)), and instead utilized biomarkers of secondary effects of the chronic stress response. Findings from previous studies using similar AL algorithms with NHANES data suggest that the AL metric is useful in describing the biological risks associated with being socially disadvantaged. For example, AL scores are higher among socially marginalized groups $[51,52]$ and AL attenuates the social gradients in ischaemic heart disease and periodontal disease [38]. Although alternate approaches to measuring AL using different metrics or applying different additive and weighting approaches have been considered [29], research indicates that no one approach has consistently stronger predictive value for different health outcomes $[26,36,53]$, particularly cardiovascular effects. Instead, $\mathrm{AL}$ is a cumulative index that characterizes the combined effects of small, subclinical changes in several physiological systems [54]. The advantage of the AL score is that it provides an integrated, biological measure of physiologic dysregulation due to chronic stress response, although it does not elucidate the dominant sources of chronic stress in the study population. Despite the methodological challenges of understanding the extent to which AL is a direct indicator of stress exposure, future research should utilize biological measures of stress response in conjunction with subjective assessments of stress exposure and objective metrics of individual and area-level SES that may act as proxy indicators of social stressors (e.g. neighborhood-level poverty rate and individual perception of community social standing) $[10,55]$. This approach could enhance understanding about the modifying potential of different chronic stressors on pollutant exposures and adverse health outcome relationships.

\section{Conclusions}

Our finding that AL may amplify the effect of blood lead on blood pressure suggests the need for more research to better understand the relevant biological and psychosocial pathways through which chemical exposures may differently affect the health of vulnerable populations, a significant portion of whom are disproportionately exposed to chronic psychosocial stressors (e.g. material deprivation, exposure to violence, lack of nutrition or access to health 
care). Cohort studies can expand exploration of mediating biological pathways, improve assessment of temporal issues, and facilitate further examination of interactive effects of environmental and social stress on other intrinsically susceptible populations (e.g. children) for other adverse health outcomes such as cognitive development, which has been linked to both chronic stress and lead exposure [40]. Most important, these results suggest that the "double jeopardy" of environmental and social stressors needs to be more systematically integrated into regulatory science and decision-making in order to better protect the health of vulnerable populations who often face disproportionate and elevated exposures to multiple chemical and non-chemical hazards.

\section{Additional files}

Additional file 1: Table S1. Adjusted difference in systolic and diastolic blood pressure by blood lead exposure among adults aged 40 to 65 years in the National Health and Nutritional Examination Survey, United States, 1999-2008

Additional file 2: Table S2. Adjusted odds ratio for elevated systolic and diastolic blood pressure by blood lead exposure among adults aged 40 to 65 years in the National Health and Nutritional Examination Survey, United States, 1999-2008 ${ }^{\text {a }}$.

Additional file 3: Table S3. Adjusted difference in systolic and diastolic blood pressure by quintiles of blood lead exposure among adults aged 40 to 65 years in the National Health and Nutritional Examination Survey, United States, 1999-2008, excluding those on antihypertensive medication.

Additional file 4: Table S4. Adjusted odds ratio for elevated systolic and diastolic blood pressure by quintiles of blood lead exposure among adults aged 40 to 65 years in the National Health and Nutritional Examination Survey, United States, 1999-2008 ${ }^{\mathrm{a}}$, excluding those on antihypertensive medication.

\section{Abbreviations}

AL: Allostatic load; CDC: Centers for disease control and prevention; Cl: Confidence interval; HPA: Hypothalamic-pituitary-adrenal; LOD: Limit of detection; NHANES: National health and nutritional examination survey; OR: Odds ratio; SES: Socioeconomic status; SE: Standard error.

\section{Competing interests}

All authors declare they have no actual or potential competing financial interests.

\section{Authors' contributions \\ RMF and EDS conceived of the study, and ARZ and RMF further specified the research question with RMF directing the study's implementation. RMF and EDS oversaw the statistical analysis and ARZ conducted all of the programming and data analysis. ARZ and RMF led the writing with significant input from EDS. All authors read and approved the final manuscript.}

\section{Acknowledgements}

This study was supported by The California Wellness Foundation, the Hewlett Foundation, the California Environmental Protection Agency, Office of Environmental Health Hazard Assessment (07-E0009 and 11-E0020), the Maternal and Child Health Bureau, Department of Health and Human Services (R40MC03600-01-00), and National Institute of Environmental Health Sciences (K99ES019881).

\section{Author details}

${ }^{1}$ Program on Reproductive Health and the Environment, University of California, San Francisco, Oakland, CA, USA. ${ }^{2}$ Department of Environmental and Occupational Health, School of Public Health and Health Services, George Washington University, Washington, DC, USA. ${ }^{3}$ Maternal and Child Health Program and Department of Epidemiology and Biostatistics, University of Maryland, College Park, Maryland, USA. ${ }^{4}$ Department of Environmental Science, Policy and Management and School of Public Health, University of California, Berkeley, California, USA.

Received: 28 August 2012 Accepted: 13 August 2013

Published: 16 August 2013

\section{References}

1. DeFur PL, Evans GW, Cohen Hubal EA, Kyle AD, Morello-Frosch RA, Williams DR: Vulnerability as a function of individual and group resources in cumulative risk assessment. Environ Health Perspect 2007, 115:817-824.

2. McEwen BS: Protective and damaging effects of stress mediators. N Engl J Med 1998, 338:171-179.

3. Gordon CJ: Role of environmental stress in the physiological response to chemical toxicants. Environ Res 2003, 92:1-7.

4. Clougherty JE, Kubzansky LD: A framework for examining social stress and susceptibility to air pollution in respiratory health. Environ Health Perspect 2009, 117:1351-1358.

5. Gee GC, Payne-Sturges DC: Environmental health disparities: a framework integrating psychosocial and environmental concepts. Environ Health Perspect 2004, 112:1645-1653.

6. Ostchega Y, Yoon SS, Hughes JTL: Hypertension awareness, treatment, and control -- continued disparities in adults: United States, 2005-2006. National Center for Health Statistics; 2008.

7. Chobanian AV, Bakris GL, Black HR, Cushman WC, Green LA, Izzo JL, Jones DW, Materson BJ, Oparil S, Wright JT, et al: Seventh report of the joint national committee on prevention, detection, evaluation, and treatment of high blood pressure. Hypertension 2003, 42:1206-1252.

8. Morello-Frosch R, Shenassa ED: The environmental "riskscape" and social inequality: implications for explaining maternal and child health disparities. Environ Health Perspect 2006, 114:1150-1153.

9. Institute of Medicine: Toward Environmental Justice: Research, Education, and Health Policy Needs. Washington, D.C: Institute of Medicine, Committee on Environmental Justice, Health Sciences Policy Program, Health Sciences Section; 1999.

10. Schulz AJ, Kannan S, Dvonch JT, Israel BA, Allen A, James SA, House JS, Lepkowski J: Social and physical environments and disparities in risk for cardiovascular disease: the healthy environments partnership conceptual model. Environ Health Perspect 2005, 113:1817-1825.

11. Gravlee CC, Non AL, Mulligan CJ: Genetic ancestry, social classification, and racial inequalities in blood pressure in Southeastern Puerto Rico. PLOS ONE 2009, 4:e6821.

12. Brook RD, Rajagopalan S, Pope CA III, Brook JR, Bhatnagar A, Diez-Roux AV, Holguin F, Hong Y, Luepker RV, Mittleman MA, et al: Particulate matter air pollution and cardiovascular disease: an update to the scientific statement from the American Heart Association. Circulation 2010, 121:2331-2378.

13. Agency for Toxic Substances and Disease Registry: Toxicological profile for lead. In Book Toxicological Profile for Lead. U.S: Department of Health and Human Services, Public Health Service; 2007.

14. Schwartz J: The relationship betwen blood lead and blood pressure in the NHANES-II survey. Environ Health Perspect 1988, 78:15-22

15. Navas-Acien A, Schwartz BS, Rothenberg SJ, Hu H, Silbergeld EK, Guallar E: Bone lead levels and blood pressure endpoints: a meta-analysis. Epidemiology 2008, 19:496-504.

16. Hertz-picciotto I, Croft J: Review of the relation between blood lead and blood pressure. Epidemiol Rev 1993, 15:352-373.

17. Cheng Y, Schwartz J, Sparrow D, Aro A, Weiss ST, Hu H: Bone lead and blood lead levels in relation to baseline blood pressure and the prospective development of hypertension: the normative aging study. Am J Epidemiol 2001, 153:164-171.

18. Vaziri ND: Mechanisms of lead-induced hypertension and cardiovascular disease. Am J Physiol-Heart Circu Physiol 2008, 295:H454-H465.

19. Navas-Acien A, Guallar E, Silbergeld EK, Rothenberg SJ: Lead exposure and cardiovascular disease - a systematic review. Environ Health Perspect 2007, 115:472-482.

20. Sparrenberger F, Cichelero FT, Ascoli AM, Fonseca FP, Weiss G, Berwanger O, Fuchs SC, Moreira LB, Fuchs FD: Does psychosocial stress cause hypertension? A systematic review of observational studies. J Hum Hypertens 2009, 23:12-19. 
21. Virgolini MB, Chen K, Weston DD, Bauter MR, Cory-Slechta DA: Interactions of chronic lead exposure and intermittent stress: consequences for brain catecholamine systems and associated behaviors and HPA axis function. Toxicol Sci 2005, 87:469-482.

22. Black PH, Garbutt LD: Stress, inflammation and cardiovascular disease. J Psychosom Res 2002, 52:1-23.

23. Clougherty JE, Levy JI, Kubzansky LD, Ryan PB, Suglia SF, Canner MJ, Wright RJ: Synergistic effects of traffic-related air pollution and exposure to violence on urban asthma etiology. Environ Health Perspect 2007, 115:1140-1146.

24. Geronimus AT: Black/white differences in the relationship of maternal age to birthweight: a population-based test of the weathering hypothesis. Soc Sci Med 1996, 42:589-597.

25. Krieger N, Sidney S: Racial discrimination and blood pressure: The CARDIA study of young black and white adults. Am J Public Health 1996, 86:1370-1378.

26. Seeman TE, Crimmins E, Huang MH, Singer B, Bucur A, Gruenewald T, Berkman LF, Reuben DB: Cumulative biological risk and socio-economic differences in mortality: MacArthur Studies of Successful Aging. Soc Sci Med 2004, 58:1985-1997.

27. McEwen BS: Protection and damage from acute and chronic stress allostasis and allostatic overload and relevance to the pathophysiology of psychiatric disorders. In Biobehavioral Stress Response: Protective and Damaging Effects. Volume 1032. Edited by Yehuda R, McEwen B; 2004:1-7. Annals of the New York Academy of Sciences].

28. McEwen BS: The neurobiology of stress: from serendipity to clinical relevance. Brain Res 2000, 886:172-189.

29. Juster RP, McEwen BS, Lupien SJ: Allostatic load biomarkers of chronic stress and impact on health and cognition. Neurosci Biobehav Rev 2010, 35:2-16.

30. Mattei J, Demissie S, Falcon LM, Ordovas JM, Tucker K: Allostatic load is associated with chronic conditions in the Boston Puerto Rican Health Study. Soc Sci Med 2010, 70:1988-1996.

31. Seeman TE, McEwen BS, Rowe JW, Singer BH: Allostatic load as a marker of cumulative biological risk: MacArthur studies of successful aging. Proc Natl Acad Sci USA 2001, 98:4770-4775.

32. Seeman TE, Singer BH, Rowe JW, Horwitz RI, McEwen BS: Price of adaptation - Allostatic load and its health consequences - MacArthur studies of successful aging. Arch Int Med 1997, 157:2259-2268.

33. Seeman T, Merkin SS, Crimmins E, Koretz B, Charette S, Karlamangla A: Education, income and ethnic differences in cumulative biological risk profiles in a national sample of US adults: NHANES III (1988-1994). Soc Sci Med 2008, 66:72-87.

34. Peters JL, Kubzansky L, McNeely E, Schwartz J, Spiro A, Sparrow D, Wright RO, $\mathrm{Nie} \mathrm{HL}, \mathrm{Hu} \mathrm{H}$ : Stress as a potential modifier of the impact of lead levels on blood pressure: The normative aging study. Environ Health Perspect 2007, 115:1154-1159.

35. NHANES 2007-2008 Public Data General Release File Documentation http://www.cdc.gov/nchs/nhanes/nhanes2007-2008/generaldoc_e.htm

36. Crimmins EM, Johnston M, Hayward M, Seeman T: Age differences in allostatic load: an index of physiological dysregulation. Exp Gerontol 2003, 38:731-734

37. Allsworth JE, Weitzen S, Boardman LA: Early age at menarche and allostatic load: data from the Third National Health and Nutrition Examination Survey. Ann Epidemiol 2005, 15:438-444.

38. Sabbah W, Watt RG, Sheiham A, Tsakos G: Effects of allostatic load on the social gradient in ischaemic heart disease and periodontal disease: evidence from the Third National Health and Nutrition Examination Survey. J Epidemiol Community Health 2008, 62:415-420.

39. National Center for Health Statistics (NCHS): Analytical and Reporting Guidelines: the National Health and Nutritional Examination Survey (NHANES). National Center for Health Statistics; 2006.

40. Cory-Slechta DA, Virgolini MB, Thiruchelvam M, Weston DD, Bauter MR: Maternal stress modulates the effects of developmental lead exposure. Environ Health Perspect 2004, 112:717-730

41. Peters JL, Weisskopf MG, Spiro A, Schwartz J, Sparrow D, Nie HL, Hu H, Wright RO, Wright RJ: Interaction of stress, lead burden, and age on cognition in older men: the VA normative aging study. Environ Health Perspect 2010, 118:505-510.

42. Glass TA, Bandeen-Roche K, McAtee M, Bolla K, Todd AC, Schwartz BS: Neighborhood psychosocial hazards and the association of cumulative lead dose with cognitive function in older adults. Am J Epidemiol 2009, 169:683-692.
43. Epel ES, Blackburn EH, Lin J, Dhabhar FS, Adler NE, Morrow JD, Cawthon RM: Accelerated telomere shortening in response to exposure to life stress. Proc Natl Acad Sci USA 2004, 101:17312-17315.

44. Lindgren KN, Masten VL, Tiburzi MJ, Ford DP, Bleecker ML: The factor structure of the profile of mood states (POMS) and its relationship to occupational lead exposure. J Occup Environ Med 1999, 41:3-10.

45. Rhodes D, Spiro A, Aro A, Hu H: Relationship to bone and blood lead levels to psychiatric symptoms: the normative aging study. J Occup Environ Med 2003, 45:1144-1151.

46. Wright RJ: Moving towards making social toxins mainstream in children's environmental health. Curr Opin Pediatr 2009, 21:222-229.

47. Nash D, Magder L, Lustberg M, Sherwin RW, Rubin RJ, Kaufmann RB, Silbergeld EK: Blood lead, blood pressure, and hypertension in perimenopausal and postmenopausal women. Jama-J Am Med Assoc 2003, 289:1523-1532.

48. Hu H, Shih R, Rothenberg S, Schwartz BS: The epidemiology of lead toxicity in adults: measuring dose and consideration of other methodologic issues. Environ Health Perspect 2007, 115:455-462.

49. Shankardass K, McConnell R, Jerrett M, Milam J, Richardson J, Berhane K Parental stress increases the effect of traffic-related air pollution on childhood asthma incidence. Proc Natl Acad Sci USA 2009, 106:12406-12411.

50. Evans GW, English K: The environment of poverty: multiple stressor exposure, psychophysiological stress, and socioemotional adjustment. Child Development 2002, 73:1238-1243.

51. Geronimus AT, Hicken M, Keene D, Bound J: "Weathering" and age patterns of allostatic load scores among blacks and whites in the United States. Am J Public Health 2006, 96:826-833.

52. Chyu L, Upchurch DM: Racial and ethnic patterns of allostatic load among adult women in the united states: findings from the national health and nutrition examination survey 1999-2004. J Women's Health 2011, 20:575-583.

53. Karlamangla AS, Singer BH, McEwen BS, Rowe JW, Seeman TE: Allostatic load as a predictor of functional decline MacArthur studies of successful aging. J Clin Epidemiol 2002, 55:696-710.

54. Juster RP, Bizik G, Picard M, Arsenault-Lapierre G, Sindi S, Trepanier L, Marin MF Wan N, Sekerovic Z, Lord C, et al: A transdisciplinary perspective of chronic stress in relation to psychopathology throughout life span development. Dev Psychopathol 2011, 23:725-776.

55. Adler NE, Epel ES, Castellazzo G, Ickovics JR: Relationship of subjective and objective social status with psychological and physiological functioning: preliminary data in healthy white women. Health Psychol 2000, 19:586-592.

\section{doi:10.1186/1476-069X-12-64}

Cite this article as: Zota et al:: Allostatic load amplifies the effect of blood lead levels on elevated blood pressure among middle-aged U.S. adults: a cross-sectional study. Environmental Health 2013 12:64.

\section{Submit your next manuscript to BioMed Central and take full advantage of:}

- Convenient online submission

- Thorough peer review

- No space constraints or color figure charges

- Immediate publication on acceptance

- Inclusion in PubMed, CAS, Scopus and Google Scholar

- Research which is freely available for redistribution 